\title{
Teatro popular criado pelas mulheres da Fortaleza da Mulher Maya (FOMMA) nos altos de Chiapas, México
}

\author{
Doris Difarnecio ${ }^{1}$ \\ Tradução: Camila Scudeler² \\ Revisão: Stela Fischer ${ }^{3}$

\begin{abstract}
Resumo
FOMMA (Fortaleza de la Mujer Maya) é um coletivo de mulheres formado em 1994 por Isabel Juarez Espinosa (Aguacatenango, Chiapas) e Petrona de la Cruz Cruz (Zinacantan, Chiapas), mulheres maias que utilizam o teatro como ferramenta para a educação e construção de comunidade. São atrizes, escritoras, dramaturgas e professoras que viajam com seus trabalhos para suas comunidades, nacional e internacionalmente, criando montagens que enfocam os direitos das mulheres e indígenas, alfabetização, sexualidade, saúde e educação em Tzeltal e tzotzil, suas línguas indígenas originárias. Seu teatro é um processo criativo, político e educativo criado por meio de testemunhos autobiográficos das atrizes que buscam representar realidades alternativas para o seu público e criar reflexão sobre os problemas sociais e emocionais que enfrentam a população indígena. Por meio da expressão corporal e da memória das atrizes documentam a maneira que vivem, pensam e lutam desde uma perspectiva de gênero.
\end{abstract}

Palavras chave: Teatro popular; indígena; gênero; identidade; memória; corpo

\section{Abstract}

FOMMA (Fortaleza de la Mujer Maya) is a collective of Mayan women formed in 1994 by Petrona de la Cruz Cruz (from Zinacantán, Chiapas) and Isabel Juárez Espinosa (from Aguacatenango, Chiapas) Mayan women who use theatre as a creative tool toward education and community building. They are performers, playwrights, and teachers who tour their work in their communities and internationally, performing plays that focus on women's and indigenous rights, literacy, health, and education in the Tzeltal and Tzotzil indigenous languages. Their theatrical work, is a creative, political and educational process based on the woman's autobiographical testimonies whose main objective is to show their audience their ability to reflect and create change from the social and emotional challenging circumstances they may face in their everyday life. Through the body expression and personal testimonies the actresses document how they live, think and resist oppression from a gender perspective.

Key Words: popular theatre; memory; body and transference

1 Diretora teatral. Mestre pelo CESMECA - Centro de Estudios superiores de México y Centro America Hemispheric Institute.

2 Atriz e professora. Mestre em Artes Cênicas na área de Pedagogia Teatral pela ECA/USP". Pesquisadora do CEPECA - Centro de Pesquisa em Experimentação Cênica do Ator- ECA/USP.

3 Doutoranda em Artes Cênicas pela Universidade de São Paulo, sob orientação da Profa. Dra. Elisabeth Silva Lopes (2013). Mestre em Artes (Teatro) pela Universidade Estadual de Campinas (2003), sob orientação do Prof. Dr. Renato Cohen. Atualmente é professora do Centro Universitário Belas Artes de São Paulo, no Curso de Comunicação Social (RTV). 


\section{Resumen}

FOMMA (Fortaleza de la Mujer Maya) es un colectivo de mujeres formado en 1994 por Isabel Juarez Espinosa ( Aguacatenango, Chiapas) y Petrona de la Cruz Cruz (Zinacantan, Chiapas) mujeres Mayas quienes utilizan el teatro como herramienta para la educación y la construcción de comunidad. Son actrices, escritoras, dramaturgas y profesoras quienes viajan con su trabajo a sus comunidades, nacional e internacionalmente haciendo montaje de sus obras que se enfocan en los derechos de las mujeres y personas indígenas, alfabetización, sexualidad, salud y educación en Tzeltal y tzotzil lenguajes indígenas. Su teatro es un proceso creativo, político y educativo creado por medio de testimonios autobiográficos de cada una las actrices, quienes buscan representar realidades alternativas a su audiencia y crear reflexión sobre los problemas sociales tanto emocionales que enfrentan la población. Por medio de la expresión corporal y la memoria las actrices documentan de que manera se vive, se piensa y se lucha desde la perspectiva de género.

Palabras claves: Teatro popular; indígena; género; identidad; memoria; cuerpo

Em 1993 começamos a organizar e planejar com outras mulheres tímidas e caladas nossa associação Fortaleza de la Mujer Maya (FOMMA). Encontramos a principal ferramenta para poder aliviar as feridas da alma em sua autoestima e em sua mente: o teatro. Por meio dos movimentos corporais se ganha a confiança entre as companheiras. Começam a praticar pelo que têm guardado por muito tempo e que até então não haviam contado pelo medo de que as próprias companheiras os revelassem Uma vez que perdem o medo da zombaria alheia e da fofoca, nos brindam com sua confiança e abrem seus corações contando o que havia acontecido em suas vidas. Muitas pessoas mudaram de uma situação de violência para uma harmonia familiar. Outras tiveram coragem de denunciar seus agressores e demandar a igualdade de gênero.

Isabel Juárez Espinosa, fundadora do FOMMA

Devido a minha formação em literatura e artes cênicas, comecei a me interessar pelo teatro como método e ferramenta tanto educativa como política. Em San Cristóbal de las Casas, Chiapas, México, trabalho desde 1999 com o grupo teatral FOMMA, Fortaleza de la Mujer Maya. Empreendemos uma colaboração artística e teatral na qual criamos cerca de 15 obras baseadas em testemunhos autobiográficos que nos permitiram experimentar diversas práticas criativas utilizando o corpo e a memória como estratégias.

Obras teatrais cujo propósito principal tem sido abrir o pensamento acerca de temas como: gênero, direitos humanos, saúde, sexualidade, alcoolismo e alfabetização. Problemáticas que em si são demandadas, principalmente nas comunidades indígenas da região de Chiapas.

Desejo contextualizar o teatro popular do FOMMA com o surgimento dos aportes teóricos e práticos de pensadores críticos durante a década de 1960 que questionaram o status quo pedagógico do momento com um forte enfoque anticapitalista, como Paulo Freire (filósofo e teórico da educação) e Augusto Boal, ator e diretor de teatro conhecido pelo desenvolvimento do Teatro do Oprimido, método a meu ver tem 
formulado uma teoria e prática de um teatro democrático, ou seja, um teatro em que o ser humano descobre que pode observar a si mesmo e, com esta descoberta, inventar uma outra maneira de se viver. Uma educação artística que promove o desenvolvimento da sensibilidade, a capacidade de expressão e criação.

O contexto histórico do teatro popular desta década nos informa sobre a relação entre atores e espectadores com objetivos centrados principalmente na luta por possibilidades de liberdade e bem estar, para melhorar as condições de vida de uma população excluída. Um ato pedagógico que constrói saberes a partir de um lugar ativo, no qual educar por meio das artes é educar para a saúde, os direitos, o bem estar e um bom viver. Este teatro é um espaço que se transforma em diálogo quando o ser humano descobre que pode, então, observar-se e, com esta descoberta, reinventa outra maneira de se comportar, de atuar.

Da mesma maneira na atualidade, as mulheres maias do FOMMA em sua trajetória teatral têm explorado e buscado a relação e a transmissão de valores para tornar visíveis as dificuldades pessoais que as mulheres indígenas encaram para empoderá-las a superar desafios.

Nas teorias que Boal fez sobre o teatro, menciona como objetivo principal que o teatro transforma o espectador em ator, o que o autor define como poética da libertação ou poética do oprimido (BOAL, 1978, p. 17). Boal afirma que o teatro é um espaço de conflito e de enfrentamento, mas também de diálogo. Paulo Freire em sua obra mais importante, Pedagogia do Oprimido (1970), disserta sobre o ato pedagógico e a concepção problematizadora da educação. Nas palavras de Freire, "a educação deve começar pela superação da contradição educador-educando" (FREIRE, 1970, p. 79). Ou seja, a "educação popular" propõe que o professor não é o único que ensina e que a ação de ensino-aprendizagem está baseada no diálogo. O professor não é um portador absoluto de conhecimento e os aprendizes não são ignorantes absolutos. Desta maneira, neste ato pedagógico, o sujeito sente que pode construir saberes e ao dar significado ao mundo, participa de sua construção. O sujeito que aprende a partir de um lugar ativo terá liberdade para transformar junto com outros, as condições que o colocam no lugar de oprimido.

Augusto Boal propõe a ruptura da passividade de um espetáculo entre o ator e o público. Propõe aos espectadores um papel ativo e participativo que devem intervir na ação teatral e, desta maneira, convertendo-se em atores sociais transformadores. 
No Teatro do Oprimido se representa uma realidade construída por outros e para os outros. Esta prática libertadora busca superar a distância entre o ator e o espectador que reproduz uma dinâmica existente entre opressores e oprimidos. De acordo com Boal, "uma vez que o ser humano conheça e torne seu corpo expressivo, estará habilitado para praticar formas teatrais que o libertem de sua condição passiva e se transforme no sujeito da ação: ator e protagonista" (BOAL, 1978, p. 27).

O teatro popular criado pelo FOMMA é uma ferramenta libertadora que permite, por meio da criação coletiva, como menciona Boal (1978), que os espetáculos sejam uma espécie de relato autobiográfico de intimidade que ao mesmo tempo, posiciona-se como uma crítica ao sistema social, cultural e político em que se veem imersas dentro de seu contexto local. Surgem como mulheres às quais sua liberdade e independência Ihes foi muito custosa, mas que decidiram viver questionando o status quo e a subordinação sob a qual têm vivido.

FOMMA é uma associação civil cujo objetivo principal é trabalhar pelo bem estar das mulheres indígenas, particularmente as viúvas, mães solteiras e crianças. Em sua sede, localizada em San Cristóbal de Las Casas, capacitam-se mulheres com oficinas de saúde, costura, panificação, alfabetização e teatro. As integrantes e fundadoras da associação, Petrona de la Cruz Cruz, Isabel Juárez Espinosa, Francisca María Oseguera, María Pérez Santiz e Victoria Patishtan, formam o grupo de teatro popular chamado Reflejo de la Diosa Luna ${ }^{4}$, uma instância criativa que lhes permite criar obras que questionam a violência e a invisibilidade dos direitos das mulheres. Através, principalmente, de testemunhos autobiográficos, as atrizes constroem personagens e obras teatrais com as quais pretendem enfrentar a discriminação e a desigualdade de gênero.

Duas das fundadoras do FOMMA, Petrona e Isabel, cujas línguas originárias são o tseltal e tzotzil, saíram ainda criança de suas comunidades Venustiano Carranza e de Zinacantán, Chiapas, e se mudaram para a cidade de San Cristóbal de Las Casas. Aos 11 e 15 anos, respectivamente, migraram buscando melhorar suas condições de vida, deixando para trás suas famílias. As duas se conheceram em uma organização indígena de escritores, Sna Jtz'ibajom, Cultura de los Indios Mayas, A.C., uma das mais antigas associações civis indígenas que trabalham sobre as tradições e as culturas dos povos indígenas em Chiapas. Por um tempo trabalharam com esta organização, majoritariamente integradas por homens, como atrizes e escritoras de 
contos e obras teatrais. Naqueles anos, Petrona escreve Una Mujer Desesperada ${ }^{5}$, obra na qual denuncia a violência e o abuso sexual que enfrentam muitas mulheres zinacantecas. Apesar de acreditar que a obra tinha méritos para que fosse montada, os membros de Sna Jtz'ibajom recusaram-se a apresentar a obra porque eram contrários em expor a violência contra as mulheres nas comunidades indígenas de sua região. Sentindo-se capazes e seguras de si mesmas, Petrona e Isabel decidem sair da Sna Jtz'ibajom e formar, com outras mulheres, um coletivo que utilizasse o teatro como principal meio de expressão. Assim nasceu o FOMMA que, desde então, tem lutado por denunciar com suas obras teatrais a marginalização e a violência de gênero. Além do teatro como fórum, oferecem uma variedade de oficinas em saúde, educação e alfabetização tanto em espanhol quanto em tsotsil e tseltal. A ideia das fundadoras, segundo Isabel Juárez Espinosa, "é que o FOMMA fosse uma organização em que o indígena pudesse lutar, na qual as mulheres pudessem seguir em frente, avançar" (Entrevista concedida à autora, em 2008).

Petrona de la Cruz Cruz ressalta que as obras de teatro que escreviam no grupo Sna Jtz'ibajom eram sobre a vida cotidiana das mulheres e sobre a história e lendas das comunidades. No entanto, quando formam seu próprio grupo, ela e Isabel Juárez dão uma volta em seu trabalho e escrevem obras, tanto coletivas quanto individuais, enfocadas na situação atual das mulheres devido a sua condição de gênero. Petrona de la Cruz Cruz diz:

No meu caso, os textos nascem da minha coragem, do que conheço, do trabalho de entrevistas que fiz com outros projetos com mulheres. Quando cheguei ao teatro comecei a escrever e a buscar tudo isso. Escrevi Una Mujer Desesperada, subi ao palco e tive uma mudança positiva de vida. 0 teatro tira de você o mal e o bom, a mim tem me ajudado muito. (Entrevista concedida à autora, em 2013.)

Por sua vez, Isabel Juárez diz, sobre a trajetória do teatro popular na organização:

Escrevemos o roteiro, chamamos a diretora para ensaiar. Há cenas fortes, de pauladas e maus tratos. Vivemos estas cenas muito intensamente, sofremos com elas, pela pobreza, pela nossa família. Se nós tivéssemos ficado na comunidade, hoje em dia teríamos muitos filhos e nada mais, estaríamos cuidando do marido e dos filhos, trabalhando a terra se a tivéssemos. No entanto, aqui há oportunidades que podemos levar para outras mulheres. Saem coisas muito positivas, muito duras, choramos e gritamos, assim é que montamos as obras. Mais do que qualquer outra coisa, quando dizemos as verdades, conscientizamos o público sobre o que todo ser humano sofre, indígena ou não indígena, de classe baixa ou alta, sendo que o que consideramos classe alta são aqueles com alto nível econômico ou de estudos. Todos nós sofremos, de uma forma ou de outra, em todo o mundo.

5 N.T.: Uma mulher desesperada 


\begin{abstract}
Aos problemas que contamos, às vezes, damos solução ali mesmo ou deixamos em suspenso para que as pessoas os analisem e busquem uma solução por conta própria. Começamos ensinando movimentos corporais, porque nas comunidades as pessoas são muito tímidas. Com os movimentos conseguimos instaurar um clima de mais confiança no grupo, daí já riem e depois falam. A confiança é muito importante. As mulheres vão tirando o que têm dentro e passam a confiar nas companheiras. Nós indígenas não contamos nossos problemas pessoais. Quando se chega já mais velho à cidade grande há uma tristeza interior em todas por terem deixado seus povos, a comunidade, a casa, tudo. Começar uma vida nova onde não há nada como o anterior, nem terra para lavrar. É como uma terapia individual, só que coletiva, para todas. É provável que em princípio não notem, mas ao final veem suas mudanças. (Entrevista concedida à autora, em 2008).
\end{abstract}

De acordo com o que apontam as integrantes do FOMMA sobre o sentido de seu trabalho, poderíamos dizer que seu teatro propõe desmantelar dispositivos políticos que reproduzem estereótipos de classe, etnia e gênero. Como referência, Mercedes Oliveira nos remete ao corpo como categoria identitária quando nos diz que:

As mulheres são reprodutoras da cultura, pois em seu papel de mães são as encarregadas de educar seus filhos dentro de um sistema de valores em que o homem tem um lugar privilegiado na família - e, portanto, uma posição de poder - e na qual existe uma divisão sexual do trabalho que gera uma jornada dupla para a mulher e promove, além disso, um modelo de submissão. (OLIVEIRA, 2008, p. 19)

Com a finalidade de contradizer e questionar os discursos de poder que as rodeiam, as atrizes buscam modos de sentir e construir a representação da verdade. Ao coletivizar a memória por meio do testemunho autobiográfico, refletem suas experiências do passado como uma passagem em direção ao presente e o futuro. Ao mesmo tempo, as condições para narrar e vivenciar os testemunhos de vida tanto individuais quanto coletivos se interpenetram para procurar representar as principais preocupações das suas comunidades como o alcoolismo, a morte materna, o machismo e a migração. Como proposto por Augusto Boal (1978), o teatro popular tem uma razão social e um motivo intencional que visa sensibilizar, mostrar sua própria realidade e problematizá-la.

A relevância da proposta teatral do FOMMA não foi suficientemente explorada até o momento para se compreender como um teatro feito por mulheres indígenas de Chiapas contribui com a transformação social, e de que maneira a crítica reflexiva criada por meio do corpo e da memória se constitui em uma ferramenta de denúncia e autodeterminação. É importante notar que os espetáculos influem e modificam técnicas corporais e conceitos de identificação. Suas caracterizações, por exemplo quando se vestem de homem, alteram as alternativas sobre representação de gênero que, ao mesmo tempo, alteram representações sobre a identidade indígena. Da mesma 
maneira, os códigos de gênero que estão sempre em relação com outras formas de identificação estão em contínuo movimento.

O FOMMA utiliza o teatro como tática e método para revelar a opressão de gênero. Suas montagens demonstram atos de violência que requerem técnicas corporais associadas com as dos homens. Como resultado, acessam e propõem uma corporalidade mais ampla e atípica em mulheres maias. Desta maneira, ilustram e trazem ao debate crítico como os códigos de gênero requerem continuidade e repetição para se manterem no poder, como defende Judith Butler (2009).

Neste sentido, mesmo que as atrizes apresentem encontros normativos entre homens e mulheres, reproduzem mais de uma categoria de gênero com as quais as mulheres possam identificar-se. A importância está no fato de que seu trabalho teatral demonstra que a identidade nunca é estática e que os corpos são atravessados por múltiplas dimensões, como identidade racial, gênero e sexualidade que lhe dão significado. Ao representar outras opções para mulheres, o teatro se converte em uma referência imediata para o político. Em outras palavras, ao pensar, refletir e encenar a partir do acervo íntimo, as mulheres se constrói seu próprio processo criativo no qual questionam e transformam uma realidade construída.

Seu teatro é criado, escrito e realizado por mulheres maias que buscam promover estratégias para o desenvolvimento da sensibilidade, da capacidade de expressão e transformação tanto nas criadoras como nos espectadores. Buscam por meio dos seus espetáculos, como o Teatro do Oprimido, que os sujeitos assumam um papel ativo sobre o que se quer trabalhar como um modo de ensaio da realidade para poder converter-se em um ator social transformador.

As integrantes do FOMMA, à margem de uma sociedade que as tem marginalizado, emergem desde a opressão para se fazer, por meio de seu trabalho teatral, mulheres que conduzem suas próprias vidas e que não buscam apenas a liberdade e o bem estar individual, mas também de outras mulheres que sofrem as mesmas condições que elas. Buscam por meio do fazer teatral e social, criar meios onde as condições de gênero e dos direitos humanos e culturais são o objetivo principal.

Para as mulheres do FOMMA foram inúmeros os fatores que influenciaram em suas vidas como os conflitos religiosos, rurais, impostos por partidos políticos, o abuso pelos kálanes e coletos $^{6}$, além dos projetos de desenvolvimento indigenista que

6 Cristóbal de las Casas, lugar onde convivem os indígenas e mestiços do qual se deriva um grupo que se 
geraram maior desigualdade, e o saque de seus recursos naturais. Como consequência, suas obras de teatro repensam a tradição e recriam identidades para enfrentar processos de homogeneização, geralmente vinculado com a discriminação e a subordinação de gênero. $O$ trabalho de reflexão do FOMMA em torno da violência que sofrem as mulheres indígenas é uma proposta vinculada com a arte e a criatividade cultural devido ao fato de conseguir evidenciar e denunciar tais condições com o objetivo de melhorar suas condições de vida. Através do teatro podem pouco a pouco atrever-se a romper o silêncio - imposto - e coletivizar suas experiências, moldando suas histórias de vida cotidiana. A fortaleza das mulheres do FOMMA se deve às raízes das experiências pessoais que não são distantes de outras mulheres. O teatro e a criação de suas obras significa para elas mais que uma linguagem, é uma maneira de repensar suas próprias vidas, um espaço onde interagir e transitar em distintos âmbitos, entre a realidade, a criatividade e o imaginário, entre o público espectador, o palco e os personagens que refletem uma realidade sobre a vida de muitos indígenas e o que as mulheres, especificamente, enfrentam.

Talvez o mais difícil seja narrar e criar obras sobre suas vidas e testemunhos. Seu trabalho teatral rejeita regras que tentam codificá-las ou silenciá-las. Mudaram a ordem sentimental que as oprimiu e o demonstram em seu processo artístico quando se vestem de homem no palco e ao narrar histórias que de acordo aos "usos e costumes" de sua comunidade devem manter-se em silêncio. FOMMA torna-se um ponto de referência para compreender as formas contemporâneas de participação política e social.

Quando a ação termina, a realidade é outra: o teatro popular do FOMMA rompe a "quarta parede", propondo estratégias de transformação dos conflitos. Propõe um instrumento para realçar, como Boal propõe em seu Teatro do Oprimido, o desenvolvimento dos direitos humanos essenciais e uma intervenção direta na sociedade para provocar o debate de uma problemática que deve ser resolvida. Transformam e intervém no espaço que separa o ator do espectador para por em prática o diálogo e a oportunidade de experimentar ideias que buscam mudar a situação de opressão e violência de gênero.

A aposta é em direção à intuição, a criatividade, a capacidade de encontrar possibilidades de como construir história sobre cultura, expressões artísticas, ritual e

auto denomina autêntico Coletos que proclamam serem os herdeiros da tradição espanhola, com certo poder socioeconômico ao serem donos de comércios e terras. Desprezam aos índios por considerá-los inferiores, tanto física como culturalmente. 
teatro, e não a partir da lógica de um conhecimento adquirido, estático e homogêneo. A memória é um exercício dinâmico, que constitui uma cidadania participativa e ativa para a ação social e política. A intervenção social do teatro popular do FOMMA permite conceber a relação com o outro, com os outros, com todos os demais. A transformação social se faz na intervenção, na troca, entre todos. Suas obras documentam de que maneira elas vivem, pensam e lutam. A memória é um exercício dinâmico, contínuo e criativo que intervém e muda, não só as atrizes e integrantes do FOMMA, mas seu público, para os quais vê-las é como ver a si mesmo.

\section{Bibliografia}

BOAL, A. Teatro del Oprimido: Teoría y Práctica. México: Ed. Nueva Imagen. 1978.

BUTLER, J. El género en disputa: El feminismo y la subversión de la identidad. México: Colección Studio-Editorial Paidós, 2009.

ERDMAN, H. Gendering Chiapas: Petrona de la Cruz Cruz and Isabel J.F. Juárez of la FOMMA (Fortaleza de la Mujer Maya/Strength of the Mayan Woman). In UNO, Roberta y Lucy Mae San Pablo Ed(s). The Color of Theatre: Race, Ethnicity and Contemporary Performance. London: Athlone Press, 2002, p. 159-170.

FREIRE, P. Pedagogy of the oppressed. New York: The Continuum International Publishing Group Inc, 2005.

OLIVERA, M. Violencia Feminicida en Chiapas: Razones visibles y ocultas de nuestras luchas, resistencias y rebeldías. México: Colección Selva Negra-UNICACH, 2008.

\section{Entrevistas}

PETRONA DE LA CRUZ CRUZ. San Cristóbal de las Casas: México, 2013.

IZABEL JUAREZ ESPINOSA. San Cristóbal de las Casas: México, 2008. 